\title{
SURVEY OF LITERATURE RELATED TO THE PROBLEMS OF GAS EMBOLISM IN HUMAN BODY*†
}

\author{
K. S. CHAN $\ddagger$ and WEN-JEI YANG \\ Department of Mechanical Engineering, The University of Michigan, Ann Arbor, Mich. 48104, U.S.A.
}

\begin{abstract}
This survey is concerned with academic and clinical researches related to the problems of gas embolism in the human body which have commonly been regarded as a dreaded complication of a variety of surgical, therapeutic and diagnostic technics. The gas emboli may be found in the human body through surgery, decompression, transfusion of oxygenerated blood, and anesthesia, etc. The survey indicates that the cases so far investigated can be classified into those in the cardiovascular, muscalar, respiratory, and reproductive systems and other parts of the human body. Most of the existing literature deals with detection, identification, prevention and treatment procedures. No apparent effort has been made on the study of their dynamic behavior in the blood, interstitial fluids and organs where they are formed. An attempt is made to prompt further research in the field of embolus dynamics by describing what needs to be investigated.
\end{abstract}

\section{INTRODUCTION}

AIR EMBOLISM is a dreaded complication in surgical, therapeutic and diagnostic procedures (Shapiro, 1965; Birch, 1950; Burrows, 1954; Cohen et al., 1951; Marshal, 1965; Pollak, 1933; Schlaepfer, 1922). Although it is relatively infrequent in medical practice, when it does occur, it is found to be so catastrophic in some cases that detailed investigation into the various aspects of the problem is considered fully warranted. In one report (Dornette, 1956) fatal venous air embolism accounted for one in one hundred and eight deaths in the operating room. Another report (Michenfelder et al., 1966) gave a rate of 2.6 per cent for air embolism during occipital craniotomy, although in these cases the patients, in whom air embolism was detected, were saved. There are also many other reports of air embolism, some of which are from abortion (Majoska, 1956; Haynes, 1956; Deadman, 1937), douching (Silver and Evans, 1968; Glassy, 1963), gunshot wounds of the neck (Ellis and Brown, 1964), operation on the bladder (Goddard and
Moffett, 1955), root canal therapy (Rickles and Joshi, 1963), craniotomy with pressurized drill (Ericsson et al., 1964), neurosurgical procedures (Hunter, 1962; Marshall, 1965), operations on the head and neck (Longnecker, 1965), antrum lavage (Thompson, 1955), air insufflation of the bladder (Mathe, 1929), joints (Kleinberg, 1927), pneumoperitorieum (Bailey, 1948, Breathnach, 1954; Burman, 1956; Higgins and Batchelder, 1961), vaginal insufflation with power blowers (Brown, 1943; Martland, 1945; Partridge, 1943; Pierce, 1936), and blood donations (Brown, 1943; Doyle and Frodsham, 1949; Devas, 1944; Levin, 1955; Reusch et al., 1960; Yeakel, 1968). Bends associated with deep sea diving has been reputedly caused by air embolism on decompression from high pressures (Hill and Greenwood, 1910; Bert, 1878; Harris et al., 1945; surgery, heart transplant, and space travel, Harvey, 1945). With the advent of open-heart particularly open-heart surgery, the possibility of air embolism is even greater (Anderson et al., 1965; Meppner, 1952, Miller and

*Received 10 January 1969.

$\dagger$ Presented at the ASME Third Biomechanical and Human Factors Division Conference at the University of Michigan, Ann Arbor, June 12-13, 1969.

¥Fulbright-Hays visiting scholar from the University of Malaya.

$\S$ Associate Professor of Mechanical Engineering. 
Allbritten, 1960, Nichols et al., 1958; Spencer et al., 1956; Starr, 1960). It is also felt that there are other possible causes of air embolism which have not yet been recognized.

Fundamentally, there are two main types of air embolism (Durant et al., 1947, 1949), namely pulmonary or venous and arterial. Arterial air embolism results from the entrance of air into the left side of the heart from the pulmonary veins or through septal defects. The air bubbles escape into the systemic arteries and the clinical manifestations depend on the site of arterial occlusion. Cardiac damage caused by air bubbles in the coronary arteries and the neurological effect of cerebral air embolism have been reported by various investigators (Friedman et al., 1962, Geoghegan et al., 1953, Goldfab and Bahnson, 1963; James et al., 1953; Landew et al., 1960). In pulmonary or venous embolism, air enters a systemic vein and is carried to the right side of the heart. Here the tolerance depends upon the quantity (Durant et al., 1945, 1947). Small amount of air may be churned into foam and carried into the lungs where it is given off; but excessive accumulation of air in the heart will cause failure to the right side of the heart and eventual death.

The amount of damages caused by gas embolism depends also on the type of gas within the bubble and in the body fluid (Maloney et al., 1958; Moore and Braselton, 1940; Nun, 1959; Munson and Merrich, 1966; Graff et al., 1959; Kunkler and King, 1959). Carbon dioxide and oxygen which have a higher solubility in blood are better tolerated. On the other hand, air which consists mainly of nitrogen is quite injurious.

The treatment of air embolism depends on the type, whether venous or arterial. Many methods have been recommended (Durant et al., 1954; Oppenheimer et al., 1953; Marshall, 1965; Nicholson and Crehan, 1956; Senning, 1952; Shires and O'Banion, 1958; Stallworth et al., 1950; Ericsson et al., 1964, Abbot, 1965; Greoghegan and Lam, 1953) and they will be discussed later.

\section{Decompression}

The earliest known cases of air embolism are associated with deep sea diving (Bert, 1878; Boycott et al., 1908). Bends which occur on rapid decompression from high pressures are reputedly caused by evolution of air bubbles in the blood stream. Bert (1878) attributed this to the release of nitrogen that has been dissolved in the body under high pressure. Hill and Greenwood (1910) and comparatively recently Gersh (1944) have cited observations of the existence of bubbles in the blood and tissues on decompression.

Similar phenomenon known as 'chokes' also occurs on decompression from atmospheric pressures to pressures corresponding to $50,000 \mathrm{ft}$ or more above sea level (Whitaker et al., 1945; Berg et al., 1945; Harris et al., 1944; Harvey, 1945). Under simulated conditions, Gersh (1944), Whitaker (1944), Berg (1944) and Harris (1944) reported finding bubbles on decompression. It has been found that formation of bubbles is more favorable on decompression from sea level pressure to that of higher altitude than from higher pressures to sea level. The formation of bubbles normally occurs in great abundance in the fatty tissues. Consequently, the fatter the individual, the higher the incidence of bubble formation. Gersh (1944) used guinea pigs for his experiments and found that bubbles were found in the fat, adrenal gland and liver. In the adrenal, bubbles were found in the cortex or in the central vein or its tributaries in the medulla. Where they occur, hemorrhage takes place in the vicinity of the bubbles. In the adrenal gland, a number of the cortical cells are ruptured; the cellular debris extending around the periphery of the bubble. Frequently, there is vascular congestion in the sinusoids peripherally placed. In the liver, only occasional small bubbles were found in the central vein of a few hepatic lobules.

However, no bubbles were found in the nerve, tendon, blood and sketal muscles. Apparently, only a few bubbles were found in 
them and these were in the neighborhood of fat cells and outside the blood vessels. Even then, the bubbles were not as large as those found in the fat tissues.

The conclusion was that lean individuals survive decompression better than fat ones. The pain and discomfort of 'bends' and 'chokes' were attributed to the distortion, extension, and rupture of the tissue fibres due to the formation of gas bubbles causing hemorrhages and local ischemia.

Harris (1944), Whitaker (1944) and Berg (1944) found that muscular activity favors bubble formation following decompression. This is attributed to high local concentration of carbon dioxide formed during muscular activity. The larger and heavier the individual, the greater the tendency. Whitaker et al. (1944) found that removal of nitrogen by breathing oxygen helps to reduce the incidence of 'bends' or 'chokes'. Harris et al. (1944) using goats found an abundance of bubbles in the heart, arteries and veins on rapid decompression. In some cases it extends to all the vascular branches, including all chambers of the heart, pulmonary arteries and veins, aorta and branches, as well as the precaval, postcaval, and hepatic portal system. In the dissected animal, decompressed to $50,000 \mathrm{ft}$ above sea level, no bubbles were visible at first in the blood vessels; but, on waiting, a sudden stream of bubbles appears coming from small branches into the larger ones. In a short time larger vessels and the heart contained a froth and were filled with gas. No bubbles were formed in larger vessels, but only from smaller veins from the limbs. No bubbles were visible in the veins from the lungs or digestive tract.

Using rats fed with fat rich food, Berg et al. (1944) found bubbles appear more readily in decompression than in normal rats.

\section{Nitrous oxide concentration}

Bubble formation arising from using nitrous oxide in anesthesia has also been reported (Eger and Saidman, 1965; Munson and Merrick, 1966). It is believed that nitrous oxide being thirty-four times more soluble than air in blood gives rise to high nitrous oxide tension in the blood. Consequently, where there are nuclei of bubbles in the blood, nitrous oxide diffuses out into the bubbles; thereby increasing its size. Hence, where air embolism is expected, administration of nitrous oxide is discouraged. Tisovec and Hamilton (1967) and Nunn (1959) found that a bubble of air actually increases several times in size when introduced into the venous blood drawn from a patient under nitrous oxide anesthesia.

\section{During general surgery}

Atmospheric air is sometimes inadvertently introduced into the circulatory system following air injection into the body for therapeutic and diagnostic procedures. Death has been reported following injection of air into the knee (Kleinberg, 1927), the male urethra (Forbes and Cordonnier, 1953; Goddard and Moffett, 1955; Mathe, 1929), presacred insufflation of air (Lefkovitz, 1957; Glassman et al., 1956), ventriculography (Meppner, 1952) and pneumoencephalography (Jacoby et al., 1953).

Injection of air into the urogenital tract in the female seems to be particularly dangerous. Death has been caused on a number of occasions by air embolism following insufflation of the vagina (Brown, 1943; Larson, 1951; Buxton, 1957; Gough, 1924; Partridge, 1943; Pierce, 1936; Martland, 1945; Breyfogel, 1945), or following attempted criminal abortion using air (Deadman, 1957; Haynes, 1956; Majoska, 1956). There have also been fatal cases without air injection (Brodsky and Greenstein, 1957; Mylks et al., 1947; Serimgeour et al., 1955; Karandy et al., 1959; McCullough, 1955).

A large number of fatal air emboli following pneumoperitoneum for the treatment of tuberculosis have also been reported (Duboczky, 1954; Burman, 1956; Cohen et al., 1951; Musgrove, 1952; Bailey, 1948). 
Dasher et al. (1954) reported 127 such cases of which 74 were fatal.

Fatal cases of air embolism arising from surgery of the head or the neck in the sitting position seem to be fairly common (Hunter, 1962; Hamby and Terry, 1952; Longnecker, 1965). Death has occurred during lavage of the nasal sinuses (Pang, 1952; Thomson, 1955; Backer, 1923), during tracheostomy (Asherson, 1958) and during thyroidectomy (Larson and Hordland, 1934). Rotem (1967) gave a case report of air embolism during insertion of transvenous endocardial pacemaker through the jugular vein. The hazard is particularly great during neurosurgery with the patient in the sitting position (Tisovec and Hamilton, 1967). Michenfelder (1966) reported a rate of 2.6 during occipital craniotomy. The particular danger in neurosurgery is that the venous sinuses associated with the brain may be held open by the supporting structure when lacerated, thus facilitating entry of atmospheric air.

Although infrequent, there are also cases of gas embolism arising from the use of hydrogen peroxide in the treatment of neonatal intestinal obstruction due to inspissated meconium (Shaw et al., 1967; Olim and Ciuti, 1954).

\section{During accidents}

There are also cases of air embolism arising from accidents involving rupture of veins. In almost all such cases, the incident is fatal since air embolism is seldom suspected and difficult to detect (Shapiro, 1965). Death has resulted from gunshot wounds of the neck (Ellis and Brown, 1964). The reason for air embolism in such cases is that often the ruptured veins have not collapsed and so offer an entrance to air. However, if either the blood pressure is so high as to fill the vein completely with blood, or so low that there is total collapse of the vein, such type of air embolism may not occur.

The most unusual cases of air embolism are, perhaps, those which are self-induced by transvestite (Cooke, 1961; Adelson, 1957).

\section{Extra corporeal circulation}

In processes involving extra corporeal transfer of blood in contact with air, gas embolism is also important (Ross, 1959; Selman et al., 1967; Mendelsohn, 1965). Instances of air embolism have been reported following pressurized transfusion of blood for increasing the process (Ruesch et al., 1960; Doyle and Frodsham, 1949; Devas, 1942; Dollen et al., 1949, Meneely and Wells, 1946; Yeakel, 1968; Bailey, 1956). Gottlieb et al. (1965), gave a detailed account of possible air embolism during blood transfusion and the various preventive measures.

In open heart surgery and heart transplant large area of body surfaces, normally covered with blood, are brought in contact with air. Therefore, following the operation some air bubbles are bound to adhere themselves to the previously exposed surface. Besides, in returning the blood into the heart, air is invariably introduced together with it. There are reports of a surprisingly large volume of air collected in the upper arc of the aorta during and after open-heart surgery (Jones et al., 1964; Carlson et al., 1967; Groves et al., 1964; Spencer et al., 1965; Anderson et al., 1965; Nichols et al., 1958). There have been cases also of air embolism arising from coronary suction when 'bubble-trap' reservoir is used during perfusion. Bubbles are frequently seen when the vacuum was increased momentarily in order to return large volumes of aspirated blood adequately (Baird and Mujagishima, 1964; Miller and Allbritten, 1960; Spencer et al., 1965).

\section{Gas embolism following hypothermia}

Gas embolism arising from hypothermia is a comparatively recent encounter in surgery. It arises in surgery during the warming up period following deep hypothermia (Donald and Fellows, 1959; Drew et al., 1959; Gordon et al., 1960). There have been reports of brain damage in children undergoing this procedure (Björk, 1960). Although it has not been proven by experiments or actual observation of 
bubbles in the human body, it has been suggested that owing to the fall of gas solubility, the high concentration of oxygen or air in the cold blood gives rise to gas evolution during the warming up period (Kaplan et al., 1962). Some researchers feel that the evolution of gaseous oxygen or air occurs even during perfusion of the normothermic body with cold blood having a high oxygen tension. Berg and his co-workers (1944), using bullfrogs, found that there was no bubble formation when the frog was cooled to $1-2^{\circ} \mathrm{C}$ and then decompressed to $50,000 \mathrm{ft}$ without warming up. However, by cooling it down to $-5^{\circ} \mathrm{C}$ to $-8^{\circ} \mathrm{C}$, then warming up to $20^{\circ} \mathrm{C}$ and decompressed, even without muscular activity, they found bubbles in the blood vessels of the legs of the frog. Their experiments gave repeatable and consistent results.

They also found that when small segments of blood-filled veins (ventral abdominal, renal portal) were tied off and removed from the frog, no bubbles were found on decompression. But when ice crystals were formed in the blood by cooling it with dry ice, and the segment decompressed, gas bubbles immediately appeared in great abundance. To show the formation of bubble nuclei on freezing, they put the blood of frogs in test tubes. If the test tube was clean, no bubbles were formed, indicating the absence of bubble nuclei. However, if the lower portion of the test tube was brought in contact with dry ice, a heavy stream of bubbles appeared as soon as ice crystals form and it came from the region of the crystals. When the ice crystals were allowed to melt, the heavy stream of bubbles ceased. They proved quite conclusively that bubble nuclei are formed on crystallization of water in blood and in the animal body.

\section{Fracture of bones and tissue}

Harvey (unpublished) found that crushing of the leg muscles in cats gave rise to bubble formation. Using bullfrogs, Berg et al. (1944), confirmed this finding and in addition found breaking of the leg bones is still more effective in bubble formation. On pounding the leg muscles of the bullfrog without rupturing the skin and decompressing it to $45,000 \mathrm{ft}$ for $10 \mathrm{~min}$ above sea level, they found bubbles in a few of the frogs. However, when the tiba or femur is broken by hand with minimum damage to tissues and without breaking the skin, decompression of the frog to $45,000 \mathrm{ft}$ resulted in bubble formation in all of the frogs. More elaborate experiments indicated formation of bubble in the region of bone fracture. Although the exact nature of the mechanism for bubble formation is not known, it was felt probably the intense mechanical agitation of the fracture caused the nuclei to be formed.

\section{TYPES OF AIR EMBOLISM}

Broadly, air embolism can be classified into two types, namely, pulmonary (venous) and arterial (James, 1961; Durant et al., 1947, 1949). In arterial embolism, air enters the left side of the heart and escapes into the systemic and coronary arteries. In the large arteries, the presence of air emboli is harmless. The bubbles are carried along with the blood into the smaller vessels. When the bubbles are small, they are very hard; and when they reach the capillary tubes of the arterial system, they are lodged in them. For this reason, even small amounts of air may cause considerable lasting damage (Geogheganand Lam, 1955; Rukstinat, 1928, 1931; Vischer, 1937; Durant et al., 1949). The occlusion of the small blood vessel by the bubble prevents blood from flowing, and this persists until the bubble is dissolved. Long lasting bubbles, therefore, may cause damage similar to thrombosis and other clinical manifestations (Benjamin et al., 1954; Boerema, 1965; Durant, 1949; Equchi and Bosher, 1962; James et al., 1953; Landew et al., 1960). Goldfarb and Bahuson (1963), using mongrel dogs, showed various degrees of cardiac damages due to small amounts of air introduced directly into the coronary arteries. Similarly, cerebral air embolism may produce permanent gross neurologic defects in the survivors (Fazio and Sacchi, 1954). 
In the case of pulmonary or venous embolism, air enters a systemic vein and is carried to the right side of the heart (Durant et al., 1947; Anderson et al., 1965; Bailey, 1956; Mandelbaum and King, 1963). The churning action of the heart on the blood converts the air-blood mixture into a foam. If the foam is not excessive, it passes into the lungs where the air is filtered out. If the amount of air is more than the heart can eliminate in this manner, it accumulates in the heart resulting in failure of the right heart. However, before the onset of cardiac failure, there are various manifestations such as rise of pulmonary artery pressure, fall of systemic blood pressure and the characteristic drumming and mill-wheel sound (Michenfilder et al., 1966; Shivpuri et al., 1959; Dasher et al., 1955; Chase, 1934; Boerema, 1965; Durant et al., 1939, 1945). Gottlieb and his coworkers (1965) gave an excellent review on venous embolism. They tabulated the dosage of air that, according to the investigators, would prove fatal, and showed the various possible situations where venous air embolism may occur and suggested their remedy. Durant and his co-workers (1947) differentiated pulmonary embolism from arterial embolism and pointed out their main differences. On the basis of experiments and observations, they recommended certain positions to adopt to help survival from air embolism. From the reports available, it seems venous embolism accounted for most of the deaths arising from air embolism. This may be because whereas in arterial embolism, unless there is a septal defect, there is very little opportunity for air to pass through the filtering action of the lungs to go into the arterial system; in the venous system, there is no such protective mechanism to stop the air from entering the right heart. It may also be because arterial embolism is more difficult to diagnose, therefore many such cases have not been detected.

Other types of air embolism such as renal and hepatic have been detected in experiments, but no clinical reports on their harmful effect are available except that of Gersh and others (1944), which attribute 'bends' and 'chokes' to it.

\section{THE GAS IN THE BUBBLE}

The amount of gas that a biological system will tolerate depends also on the type of gas in the bubble (Gottlieb et al., 1965; Kunkler and King, 1959; Harkens and Harmon, 1934; Graff et al., 1959). In his comparative study of air, oxygen and carbon dioxide using live dogs, Kunkler and King (1959) found that air and oxygen characteristically produced emboli which were stable and offered obstruction. As soon as the emboli ceased to move, they remained permanently in those positions. With other emboli joining them, long immobile columns of air or oxygen would soon form in the coronary arteries preventing blood from flowing. On the other hand, carbon dioxide emboli would rapidly travel the extent of the artery and disappear. When large amounts of carbon dioxide were given, the emboli would pause at a bifuration point and then proceed rapidly. When too much carbon dioxide was given, a long column of it would become immobile, block the artery and behave essentially as an air embolus. They found carbon dioxide is five times and oxygen two times better tolerated than air when injected directly into the left ventricle. They attributed the difference to the solubility of carbon dioxide in water which is thirty-four times greater than that of air. Their results agreed well with those of Fries et al. (1957), Harkens and Harmon (1934), Moore and Braselton (1940). It is also believed that when a carbon dioxide bubble becomes stable, it is no more a pure carbon dioxide bubble because other gas would have diffused into it. In the case of oxygen, no definite explanation can be given for its higher tolerance. The conclusion is drawn from the results of experiments conducted on live animals. In some cases, particularly when oxygen is injected directly into the right side of the circulation, the results 
are not so conclusive (Harkens and Harmon, 1934).

\section{TREATMENT AND PROPHYLACTIC MEASURES}

The remedy for air embolism depends on the nature and circumstance of embolism. In the case of 'chokes' and 'bends' arising from decompression, recompression and muscular activity to improve circulation have been recommended (mentioned by Harris et al., 1945; Boycott et al., 1908). However, on the evidence provided by the experiments of Harris et al. (1945), muscular activity seems to aggravate the situation and should, therefore, be discouraged. Lemire and his associates (1968), who do not attribute 'bends' to evolution of bubbles, recommend replacement of plasma which, according to them, escapes into the tissues surrounding the blood vessels on decompression and causes 'bends'. Bauer et al. (1965) recommended hypothermic treatment of 'chokes'.

In the case of air embolism in the circulatory system, preventive measures are widely recommended. These include changes of design in equipment which have so far proved to be giving rise to air embolism (Bailey, 1956; Brown et al., 1958). Gottlieb et al. (1965) gave a detailed description of the equipment, their defects, and the recommended changes of design. The use of carbon dioxide gas to flood the operation field has been widely recommended for open-heart surgery (Burbank et al., 1965; Eguchi et al., 1963; Selman et al., 1967). This method seems to be in popular use nowadays. Where air embolism is suspected, avoidance of nitrous oxide as an anesthetic is strongly advocated so as to prevent diffusion of nitrous oxide into the bubble nucleus (Eger and Saidman, 1965; Munson and Merrick, 1966).

However, as pointed out by various investigators, in practice air invariably enters the circulatory system in one way or another (Bailey, 1956; Gottlieb et al., 1965). In the case of pulmonary embolism, and without opening the chest cavity, Durant et al. (1954) recommended placing the body in the left lateral position to help displacement of air from the right ventricle. For arterial embolism, they recommended placing the body head downwards. However, when access to the heart is made possible, massage of the heart is also widely recommended (Geoghegan and Lam, 1953; Ericsson et al., 1964). Jones and Cross (1964) gave the following methods as being useful to combat complication during cardiac surgery: (1) Filling the left heart with fluid (Swan et al., 1950), (2) insertion of a left arterial vent (Groves and Effer, 1964), (3) inducing ventricular fibrillation during the period that the heart is open (Glenn and Sewall, 1953), (4) holding the mitral valve incompetent with a special instrument (Gott and Lillehei, 1959) and (5) introduction of a vent into the left ventricle (Stallworth et al., 1950).

The use of a transvenous catheter for the aspiration of the entrapped air is also in common practice (Tisovec and Hamilton, 1967; Michenfelder et al., 1966). Correction of cerebral air embolism by regional perfusion with dextran is also recommended (Abbot et al., 1965).

\section{FUTURE WORK}

In the previous sections, the sources of gas embolism, the means for detecting and identifying gas emboli and the mechanical means being adopted or attempted to eliminate these gas emboli are summarized. However, it is an overstatement to say that there is neither a sure means of safeguarding against gas embolism nor a perfect precaution in preventing the formation of gas emboli. If such is the case, the knowledge about the mechanism of growth or collapse of gas emboli in the extracorporeal circulatory systems connected to the human body as well as various organs inside the human body may be of importance for clinical and academic research. In the following, an attempt is made to stimulate possible interest in the study of the mechanism by suggesting what should be done. 


\section{Dynamics of gas emboli in body fluids and} organs

In the past, some studies have been conducted on the statics of gas emboli in the body fluids and organs, notably by Harvey and his associates (1944). The principal interest was to determine the size of a spherical gas bubble under equilibrium conditions using the relation $R=\Delta p / 2 \sigma$, where $R$ is the bubble radius, $\Delta p$ is the pressure difference between the gas inside the bubble and the surrounding liquid, and $\sigma$ the gasliquid surface tension. Ironically, those gas emboli which are potentially hazardous or which may cause the problem of embolism are never in an equilibrium condition with its surrounding media. For example, a gas embolus which enters the left ventricle is obviously not at rest. It has been moving with the circulating blood and as a result it has moved from a location with higher blood pressure to another location with lower blood pressure. In other words, the embolus is subject to the pressure force which has been changing with location and time. The gas embolus is now under dynamical conditions and therefore the equation $R=\Delta p / 2 \sigma$ is of no use at all.

The main purpose of the study of the dynamic behavior of gas embolus is to determine the parameters controlling its growth or collapse. The characteristic parameters of gas embolism include the viscosity, thermal conductivity and compressibility of the liquid, the shape and surface tension of the gas embolus, the composition and thermodynamic behavior of the gas inside the embolus, the thermal and mass diffusivity of the gas across the embolus surface into the liquid, etc. The diffusion of heat plays an important role especially in the combined operation of whole-body perfusion and intraarterial cooling. It may cause not only an increase in the tension of oxygen in the equilibrated medium but also an increase in the gas pressure inside the embolus. The growth of the embolus under the influence of a pressure field depends significantly on the diffusion of gas in and out of the embolus. Probably the physical properties of a liquid having an important effect on the dynamics of gas embolus are its viscosity and thermal conductivity. The viscosity of the liquid is instrumental in the consumption of the mechanical energy such as the kinetic energy, the rate of work done by the pressure on the embolus surface, etc. On the other hand, the compressibility of the liquid probably plays a minor role in bubble dynamics. The deviation of the embolus surface from a spherical shape is often decisive in determining how a collapsing bubble will behave, while the surface tension probably strongly influences the violence with which an embolus collapses. The composition of the gas inside the embolus is essential for the determination of the partial pressure of the embolus contents, while its thermodynamic behavior is an essential part of any realistic discussion of embolus phenomena.

\section{Coefficient of diffusion of gas through embolus surface into body fuids}

In medical science, as in many other related fields, the term 'solubility' is extensively used; for example, to express the amount of oxygen dissolved in a unit volume of blood. But it has occasionally been used to indicate, or at least imply, the speed or rate at which a gas may dissolve into a liquid. For example, it was reported by Kunkler and King (1959) that comparison of air, oxygen and carbon dioxide embolization shows oxygen to be tolerated about two times and carbon dioxide five times better than air. This was deduced from the observation that carbon dioxide, when compared with air, is more than thirty times more soluble in blood. According to the natural law of mass transfer, the rate of . diffusion per unit area is determined by the product of the coefficient of diffusion and the concentration difference. In other words, for a given concentration difference between the gas phase inside the embolus and the 
surrounding liquid, the rate at which the gas moves in or out of the embolus is determined by the coefficient of diffusion of the gas into the liquid. To the knowledge of the authors, the coefficients of diffusion of gases such as air, oxygen and carbon dioxide into the blood or other body fluids have not yet been determined. Since mass diffusion across the embolus surface is one of the most important parameters which determine the rate of embolus collapse or growth, the diffusion coefficient can be regarded as an important physical property to be explored.

\section{Possible damages by liquid pressure variation}

It is well known in engineering that the collapse of gas bubbles may cause considerable damage to the surfaces containing the liquid in which the bubbles are situated. This is called the cavitation damage. There are two representative schools of thought about the mechanism which may have caused such damage: the generation of shock waves in the liquid induced by the collapse of a spherical bubble and the generation of liquid jet caused by the collapse of an asymmetrical (nonspherical) bubble. Both schools have considerable evidence to support their respective views although neither is decisive. During the collapse of a gas bubble in body fluids, especially in blood, a significant change in the liquid pressure as well as the rate of the change have been disclosed, particularly near the end of the collapse stage. It is conjectured that the change in the liquid pressure may cause damage to the blood vessel, blood cells, and body tissues which are within the area of 'influence' of the collapsing bubble. If the conjecture is found to be true, then gas emboli in the human body can cause two hazards: gas embolism and damage caused by the collapse of the emboli. Up to the present date, the authors have not been aware of any reports suggesting such damages caused by the collapse of gas emboli; but it is worthwhile to examine the possibility.
4. Addition of a foreign agent into the blood stream in the presence of gas emboli

Munson and Merrick (1966) have indicated that air-filled cavities within the body may increase in volume and/or pressure during nitrous oxide anesthesia. This is due to the fact that the presence of nitrous oxide in the blood has caused a change in certain physical properties, such as the coefficient of diffusion, the surface tension and viscosity of the blood, etc. The results of their experiments, although ominous from the view point of gas embolism (because the gas embolus increases in size instead of disappearing), suggest the feasibility of reducing the embolus size or accelerating the collapse of the embolus by means of adding a foreign agent into the blood. The harmless foreign agent should possess the characteristics such that its presence may change the physical properties in favor of accelerating the collapse of the gas embolus. For example, should the gas-liquid surface tension be reduced by the addition of a foreign agent, the radius of the gas embolus for a given $\Delta p$ will be reduced according to the expression $R=2 \sigma / \Delta p$. In the presence of such an agent, the coefficient of diffusion should be examined as a function of composition (the ratio of the amount of the agent added to the total weight including the original liquid).

\section{The problem of bubble formation}

For a bubble formed in the human body, the subsequent behavior in its life-time history is closely related to the mechanism of its formation. Harvey and his associates (1944) have made a significant contribution to the understanding of bubble formation in animals by introducing the knowledge available in engineering science to biological systems. In their study, the organs in which bubbles form are identified and the physical factors primarily responsible for bubble formations are examined. However, the results are qualitative in nature and an ideal liquid (water is considered as an ideal frictionless liquid) is employed in the discussion for the stability 
and growth of gas nuclei. There is no doubt that the body fluids behave entirely different from an ideal liquid. For the purpose of understanding the mechanism of bubble formation, it is desirable that additional studies be conducted to obtain quantitative information on the inception and thresholds for bubble formation in body fluids or organisms.

Acknowledgement-The work reported was supported by a grant from the Michigan Heart Association to which the authors wish to express their appreciation.

\section{REFERENCES}

Abbot, O. A., Exarkos, N. and Aydin, K. (1965) Immediate correction of cerebral air embolism by regional perfusion with dextran: experimental and clinical observations. Ist A. Mtg, The Soc. of Thoracic Surgery, St. Louis, Missouri.

Adelson, L. (1957) Fatal air embolism following intrascrotal infection in a transvestite. J. forens. Sci. 2, 291-295.

Anderson, R. M., Fritz, J. M. and O'Hare, J. G. (1965) Pulmonary air emboli during cardiac surgery. J. thorac. cardiovasc. Surg. 49, 440-449.

Asherson, N. (1958) Tracheostomy: Sudden death from air embolisms. J. Lar. 72, 743-745.

Austen, W. G., Wilcox, B. R. and Bender, H. W. (1964) Experimental studies of the cardiovascular response secondary to the injection of augiographic agents. $J$. thorac. cardiovasc. Surg. 47, 356-366.

Austen, W. G., Howry, D. H. (1965) Ultrasound as a method to detect bubbles or particular matter in the arterial line during cardiopulmonary by-pass. J. surg. Res. 5, 283-284.

Bacher, J. A. (1923) Fatal air embolism after puncture of the auxillary antrum. Calif. Med. 21,433 ......

Bailey, H. (1948) Air embolism in pneumoperitoneum report of a fatal case. Am. Rev. Tuberc. 57,621-625.

Baird, R. T. and Miyagishima (1964) The damper of air embolism through pressure perfusion cannula. J. thorac. cardiovasc. Surg. 46, 2, 212-219.

Bauer, R. O., Campbell, Goodman, R., Munsat, T. L. and Pops, M. A. (1965) Aeroembolism treated by hypothermia. Aerospace Med.36, 671-675.

Behnke, A. R. (1942) Physiologic studies pertaining to deep sea diving and aviation, especially in relation to fat content and composition of boyd. Harvey Lect. Ser. 37, 198-226.

Benjamin, R. B., Lurbok, C. and Lewis, F. G. (1957) The effects of air embolism in the systemic circulation and its prevention during open-heart surgery. $J$. thorac. Surg. 34, 548-552.

Berg, W. E., Harris, M., Whitaker, D. M. and Twitty, V. C. (1945) Additional mechanism for the origin of bubbles in animals decompressed to simulated altitudes. J. gen. Physiol. 28, 253-258.

Bert, P. (1878) La Presion Barometrique. Masson, Paris.
Birch, C. A. (1950) Air embolism. Practitioner 165, 164-170.

Bjork, V. O. (1960) An effective blood heat exchanger for deep hypothermia in association with entracorporeal circulation but excluding the oxygenator. $J$. thorac. cardiovasc. Surg. 40, 237-252.

Boerema, B. (1965) Appearance and regression of pulmonary arterial leisons after repeated intravenous injections of gas. J. Path. Bact. 89, 741-744.

Boycott, A. E., Damant, G. C. C. and Holdane, J. S. (1908) The prevention of compressed air illness. J. Hyg. 8, 342-443.

Boycott, A. E. and Damant, G. C. C. (1908) Experiments on the influence of fatness on susceptibility to caissondisease. J. Hyg. 8, 445-456.

Breathnach, C. S. (1954) Air embolism in preumother apeutics. Ir.J. med.Sci. 11, 403-413.

Breyfogle, H. S. (1945) Death from air embolism following insufflation during pregnancy. J. Am. med. Ass. 129, 342-344.

Brodsky, J. D. and Greenstein, L. (1951) Air embolism associated with pregnancy and the puerperuim. Illinois med. J. 112, 1-6.

Brown, R. L. (1943) Fatal embolism after insufflation of vagina. Lancet 1, 616 .

Brown, I. W., Jr., Smith, W. W. and Emmons, W. O. (1950) An efficient blood heat exchanger for use with extracorporeal circulation. Surgery 44, 372-377.

Browne, G. F. (1943) Intravenous injection of air fatal to blood donor. Anesthesiol. 4, 202-205.

Burbank, A., Ferguson, T. B. and Burford, T. H. (1965) Carbon dioxide flooding of the chest in open heart surgery. J. thorac. cardiovasc. Surg. 50, 691-698.

Burman, D. (1956) Air embolism during pneumoperitoneum treatment. Thorax 11,49-56.

Burrows, E. H. (1954) Fatal air embolism. S. Afr. med.J. 28, 436-439.

Burstein, C. (1960) Cardiovascular collapse due to air embolism. Clinical Anesthesia Conference, N. Y. med. J. 60, 97-99.

Buxton, C. L. (1957) Death from air embolus. Report of a case following tubal insufflation. Am. J. Obstet. Gynec. 74, 430-433.

Carlson, R. G. and Lillehei, C. W. (1967) A useful modification of the aortic needle-vent for prevention of air embolism during open-heart surgery. $J$. thorac. cardiovasc. Surg. 53, 848-849.

Chase, W. H. (1934) Anatomical and experimental observations on air embolism. Surgery Gynec. Obstet. 59, 569-577.

Clark, L. C., Jr., Kaplan, S., Matthews, G. C., Edwards, F. K. and Helmsworth, J. A. (1951) Monitor and control of blood oxygen tension and $\mathrm{pH}$ during total bodyperfusion. J. thorac. cardiovasc. Surg. 36, 488-496.

Cohen, A. C., Glinsky, G. C., Martin, G. K. and Fetterhoff, K. J. (1951) Air embolism, Ann. Intern. Med. 35, 779-784.

Cooke, R. T. (1961) Self-Induced air embolism in a man. Br. med.J. 2, 1197.

Dasher, W. A., Black, J. P. M., Weiss, W. and Bogen, Z. (1954) Air embolism complicating pneumoperiteneum. Am. Rev. Tuberc. 69, 396-405. 
Dasher, W. A., Weiss, W. and Bogen, Z. (1955) The electrocardiographic pattern in venous air embolism. Dis. Chest. 27, 542-546.

Deadman, W. J. (1937) Total air embolism-care reports. Can.med.Ass.J. 37, 157-160.

Dean, R. B. (1944) The formation of bubbles. J. appl. Phys. 15, 446.

Devas, M. B. (1942) Air entry through transfusion sets. Lancet 2, 154-155.

Dolteu, Z. G., Gardner, E. and Wylie, W. D. (1945) Fatal air embolism during blood transfusion. Lancet 1, 531-532.

Donald, D. E. and Fellows, J. L. (1959) Relation of temperature gas tension and hydrostatic pressure to the formation of gas bubbles in extracorporeally oxygenated blood. Surg. Forum Am. Coll. Surg. 10, 589-592.

Donald, D. E. and Fellows, J. L. (1961) Physical factors relating to gas embolism in blood. J. thorac. cardiovasc. Surg. 42, 110-118.

Dornette, W. H. L. and Orth, O. S. (1956) Death in the operating room. Curr. Res. Anesth. Analg. 35, 545-569.

Doyle, G. B. and Frodsham, P. (1949) Fatal air embolism during blood transfusion. Lancet 1, 735-736.

Drew, C. E., Keen, G. and Benazon, D. B. (1959) Profound hypothermia. Lancet 1, 745-747.

Drew, C. W. and Anderson, I. M. (1959) Profound hypothermia in cardiac surgery, Lancet 1, 748-750.

Duboczky, B. O. (1954) Loud mill-wheel murmur presumably caused by air embolism in a patient with pneumoperitoneum. Am. Rev. Tuberc. 70, 1092-1095.

Duff, F., Greenfield, A. D. M. and Whelan, R. F. (1953), Vasodilatation produced by experimental arterial gas embolism in man. Lancet 2, 230-234.

Durant, T. M., (1935) The occurrence of coronary air embolism in artificial pneumothorax. Ann. intern Med. $8,1625-1632$.

Durant, T. M., Ginsberg, I. W. and Roesler, H. (1939) Transient bundle branch block and other electrocardiographic changes in pulmonary embolism. Am. Heart J. 17, 423-430.

Durant, T. M., Lang, J. and Oppenheime, M. J. (1945) The electrocardiogram of acute right ventricular ischemia produced by air embolism. Fedn. Proc. 4, 18 .

Durant, T. M., Long, J. and Oppenheime, M. J. (1947) Pulmonary (venous) air embolism. Am. Heart J. 33, 269-281.

Durant, T. M., Oppenheimer, M. J., Webster, M. R. and Lang, J. (1949) Arterial air embolism. Am. Heart J. 38, 481-500.

Durant, T. M., Oppenheime, M. J., Lynch, P. R., Oscanio, G. and Webber, D. (1954) Body position in relation to venous air embolism: a roentgenologic study. Am. J. med.Sci. 227, 509-520.

Durant, T. M. and Oppenheime, M. J. (1957) Embolism due to air and other gas. Veterans Administration Department of Medicine and Surgery Medical Bull. No. MB-1.

Eger, E. I., II and Saidman, L. J. (1965) Hazards of nitrous oxide anesthesia in bowel obstruction and pneumothorax. Anesthesiology 26, 61-66.

Eguchi, S. and Bosher, L. H., Jr. (1962) Myocardial dysfunction resulting from coronary air embolism. Surgery 51, 103-111.

Eguchi, S., Sahurai, Y. and Yamaguchi, A. (1963) The use of $\mathrm{CO}_{2}$ gas to prevent air embolism during open heart surgery. Acta med. Biol. (Niigata) 11, 1-13.

Eiseman, B., Baxter, B. J. and Prachuabmoh, K. (1959) Surface tension reducing substances in the management of coronary air embolism. Ann. Surg. 149, 374-380.

Ellis, G. R. and Brown, J. R. (1964) Massive air embolism due to gunshot wound. J. Am. med. Ass. 189, 953-955.

Emery, E. R. J. (1962) Air embolism A report of two cases, one treated successfully. Anaesthesia 17, $455-466$

Ericsson, J. A., Gottlieb, J. D. and Sweet, R. B. (1964) Closed chest cardiac massage in the treatment of venous air embolism. New Engl.J. Med. 270, 1353-1354.

Fazio, C. and Sacchi, U. (1954) Experimentally produced red softening of the brain. I. Neuropath exp. Neurol. $13,476-481$.

Fine, J. and Fischmann, J. (1940) Experimental study of treatment of air embolism. New Engl. J. Med. 223, 1054-1057.

Forbes, K. A. and Cordonnier, J. J. (1953) Circulation collapse following Urethrocystography. J. Urol. 70, 975-979.

Friedman, 1. H., Gelman, S., Lowenfels, A. B., Landew, M. and Lord, J. W. (1962) The effects of intra-arterial microbubbles on normothermic and hypothermic dogs. J. surg. Res. 11, 19-25.

Fries, C., Levowitz, B., Adler, S., Cook, A., Kartson, K. and Dennis, C. (1957) Experimental cerebral gas embolism. Ann. Surg. 145, 461-470.

Geoghegan, T. and Lam, C. R. (1953) The mechanism of death from intra cardiac air and its reversibility. $A n n$. Surg. 138, 351-359.

Gersh, J., Hawkinson, G. E. and Ratbun, E. N. (1944) Tissue and vascular bubbles after decompression from high pressure atmospheres-correlation of specific gravity with morphological changes. J. cell. com. Physcol. 24, 35-61.

Glassman, J., Shapiro, R. and Robinson, F. (1956) Air embolism during presacrol pneumography. $J$. Urol. 75, 569-571.

Glassy, F. J. (1963) Coroner's corner. Med. Times 91, 63a.

Glenn, W. L. and Sewall, W. H. (1953) Experimental cardiac surgery-IV. The prevention of air embolism in open heart surgery: repair of intra-atrial septal defects. Surgery 34, 195-206.

Goddard, D. W. and Moffett, J. D. (1955) Fatal air embolism during urologic operation. J. Urol. 73, 613-618.

Goldfarb, D. and Bahnson, H. T. (1963) Early and late effects on the heart of small amounts of air in the coronary circulation. $J$. thorac. cardiovasc. Surg. 46, $368-378$.

Gordon, A. S., Jones, J. C. and Luddington, L. G. (1960) Deep hypothermia for intracardiac surgery. Am. J. Surg. 100, 332-337.

Gordon, A. S., Meyer, B. W. and Jones, J. C. (1960) Open-heart surgery using deep hypothermia without an oxygenator. J.thorac. cardiovasc. Surg. 40, 787-799.

Gott, V. L. and Lillehei, C. W. (1959) An instrument for the prevention of air embolism during direct vision 
closure of atrial septal defects and mitral valvulop. Surgery Gynec. Obstet. 108, 747-750.

Gottlieb, J. D., Ericsson, J. A. and Sweet, R. B. (1965) Venous air embolism. Anesth. Analg. curr. Res. 44, 773-779.

Gough, J. A. (1924) Air embolism in obstetrics. Surgery. Gynec. Obstet. 31, 27-31.

Graff, T. D., Arbegast, N. R., Phillips, O. C., Harris, L. C. and Frazier, T. M. (1959) Gas embolism, A comparative study of air and carbon dioxide as embolic agents in the venous system. Am. J. Obstet. Gynec. 78, 259-265.

Groves, L. K. and Effler, D. B. (1964) A needle-vent safe guard against systemic air embulus in openheart surgery.J. thorac. cardiovasc. Surg. 47, 349-355.

Hamby, W. B. and Terry, R. N. (1952) Air embolism in operations done in the sitting position; a report of five fatal cases and one of rescue by a simple maneuver. Surgery 31, 212-215.

Hare, H. A. (1902) The entrance of air into the veins. Am.J. med.Sci. 124, 843-847.

Harkens, H. and Harmon, P. (1934) Embolism by air and oxygen: experimental studies. Proc. Soc. exp. Biol. Med.32, 178-181.

Harris, M., Berg, W. E., Whitaker, D. M., Twitty, V. C. and Blinks, L. R. (1945) Carbon dioxide as a facilitating agent in the initiation and growth of bubbles in animals decompressed to simulated attitudes. J. gen. Physiol. 28, 225-240.

Harris, M., Berg, W. E., Whitaker, D. M. and Twitty, V. C. (1945) The relation of exercise to bubble formation in animals decompressed to sea level from high parometric pressure. J. gen. Physiol. 28, 241-251.

Harvey, Z. N., Barnes, D. K., McElroy, W. D., Whiteley, A. H., Pease, D. C. and Cooper, K. W. (1944) Bubble formation in animals-I. J. cell. comp. Physiol. 24, $1-22$.

Harvey, E. N., Whiteley, A. H., McElroy, W. D., Pease, D. C. and Barnes, D. K. (1944) Bubble formation in animals-II.J. cell. comp. Physiol. 24, 23-34.

Harvey, Z. N. (1945) Decompression sickness and bubble formation in blood and tissues. Bull. N.Y. Acad. Med. 21, 505-536.

Haynes, D. M. (1956) Cerebral hyposcia from air embolus following attempted abortions. Am.J. Obstet. Gynec. 71, 1111-1113.

Higgins, G. A. and Batchelder, T. L. (1961) Air embolism following transdiaphragmatic pneumoperitoneum. I. thorac. cardiovasc. Surg. 41, 159-161.

Hill, L. (1912) Caisson Sickness. Longmans, Green, New York.

Hill, L. and Greenwood, M. (1910) On the formation of bubbles in the vessels of animals submitted to a partial vacuum. J. Physiol. (1909-1910) 39, XXii.

Hodges, P. R. D., Sellers, J. L., Stony, P. H., Stanley, F. T. and Lillehei, C. W. (1965) The effect of total cardiopulmonary by-pass procedures upon cerebral function evaluated by the electroencephalogram and a blood brain barrier test, Extracorporeal Circulation. C. C. Thomas, Springfield, Ill.

Horton, J. A., Inkster, J. S., Mackenzie, A. and Pask, E. Z. (1953) Intra-arterial transfusion. Br. med. J. 2, 1294-1297.
Hunter, A. R. (1955) Problems of anesthesia in artificial pneumothorax. Proc. R. Soc. Med. 48, 765-768.

Hunter, A. R. (1962) Air embolism in the sitting position. Anaesthesia 17, 467-472.

Jacoby, J. J., Geiling, E. M. K. and Livingstone, H. M. (1948) Intra venous nitrous oxide and experimental embolism: a preliminary report. Anesth. Analg. 27, 13-24.

Jacoby, J., Jones, J. R., Leigler, J., Classen, L. and Garvin, J. P. (1959) Pneumoencephalography and air embolism: simulated anesthetic death. Anesthesiology 20, 336-340.

James, T. N., Geoghegan, T. and Lam, C. R. (1953) Electrocardiographic manifestations of air in the coronary arteries of dying and resuscitated hearts. Am. Heart J. 46, 215-228.

James, T. N. (1961) Air embolism. Am. Heart J. 61, 423-424.

Jones, R. D. and Cross, F. S. (1965) A vent valve to minimize air embolism during open-heart surgery. J. thorac. cardiovasc. Surg. 48, 310-313.

Kaplan, S., Clark, L. C., Matthews, E. C., Edwards, F. K., Schwab, L. and Helmsworth, J. A. (1958) A comparison of the results of total body perfusion in dogs during potassium citrate cardiac arrest, sinus rhythm and induced ventricular fibrillation. Surgery 43, 14-23.

Kaplan, S., Clark, L. C., Fox, R. P., Daoud, G. and Shemtob, A. (1962) Oxygen embolization during deep hypothermia. Archs Surg. 84, 140-147.

Karandy, E. J., Dick, J. H., Dwyer, R. P. and Mckinnon, H. J. (1959) Fatal air embolism. Am. J. Obstet. Gynec. $78,96-99$.

Keeri-Szanto, M. and Rinfret, G. (1957) Circulatory arrest during surgery of the posterior cranial forsa. Anaesthesia 12, 317-320.

Kerr, J. H. (1958) Pneumatic hazards of intravenous therapy. Surg. Gynec. Obstet. 107, 792-794.

Kimbler, A. and King, H. (1959) Comparison of air, oxygen and carbon dioxide embolization. Ann. Surg. 149, 95-99.

Kleinberg, S. (1927) Pulmonary embolism following oxygen injection of a knee. J. Am. med. Ass. 89, 172-173.

Landew, M., Bowles, L. T., Gelman; S., Lowenfels, A. B., Tepper, R. and Lord, J. W., Jr. (1960) Effects of intra arterial microbubbles. Am. J. Physiol. 199, 485-490.

Larson, L. M. and Nordland, M. (1934) Air embolism complicating thyroidectomy. Ann. Surg. 99, 112-115.

Larson, C. P. (1951) Venous air embolism. Am. J. clin. Path. 21, 247-250.

Lefkovitz, A. M. (1957) Fatal air embolism during presacral insufflation of air. J. Urol. 77, 112-115.

Lemire, G., Koven, T., Chen, C. H. and Drucker, W. R. (1968) Gas embolism is not the cause of bends. J. Am. med. Ass. 203, 31.

Levin, J. (1955) Certain aspects of transfusion under pressure. S. Afr. med.J. 29, 184-186.

Longnecker, C. G. (1965) Venous air embolism during operation on the head and neck. Plastic reconstr. Surg. 36, 619-621.

Lucas, M. (1936) Air emboli in coronary arteries following artificial pneumothorax in a $30-y r$ old patient. 
Beitr. Klin. Tuberk. 88, 223-228.

Majoska, A. V. (1956) Air embolism fatalities in criminal abortions. Hawaii med.J. 15, 451-453.

Malette, W. C., Fitzgerald, J. B. and Eiseman, B. (1960) Aero-embolus: A protective substance. Surg. Forum 11, 155-156.

Maloney, J. V., Jr., Longmire, W. P., Jr., Schmutzen, K. S., Marable, S. A., Raschke, E., Walanobe, Y., Lobpreis, E. L. and Aryouman, J. E. (1958) An experimental and clinical comparison of the bubble dispersion and stationary screen pump oxygenators. Surgery Gynec. Obstet. 107, 577-587.

Maudelbaum, T. and King, H. (1963) Pulmonary air embolism. Surg. Forum 14, 236-238.

Marchand, P., Van Hasselt, H. and Luntz, C. H. (1964) Massive venous air embolism. S. Afr. med. J. 38, 208.

Marshall, B. M. (1965) Air embolism in neurosurgical anesthesia, its diagnosis and treatment. Can. Anaesth. Soc. J. 12, 255-261.

Mathe, C. P. (1929) Fatal embolus due to insufflation of bladder with air. Surgery Gynec. Obstet. 48, 429-436.

Martland, H. S. (1945) Fatal air embolism due to powder insufflation used in gynecological treatments. $A m . J$. Surg. 68, 164-169.

Martland, H. S. (1945) Air embolism: with special reference to its surgical importance. Am. J. Surg. 68, 281-286.

Martland, H. S. (1945) Deathfromair embolism following insufflation during pregnancy. J. Am. med. Ass. 129, 905.

McCullough, K. M. and Morales, E. (1955) Air embolism following post-parlum surgical sterilization. $M d$ med. $J$. 4, 273-274.

McDonald, R. T. (1959) A simple and safe method for the prevention of air embolus during transfusion. Henry Ford Hosp. med. Bull. 71, 24-26.

McNicol, M. W. and Campbell, E. J. M. (1965) Severity of respiratory failure, Arterial blood-gases in untreated patients. Lancet 1,336-338.

Mendelsohn, D. (1965) Discussion on oxygenators. Extracorporeal Circulation. pp. 120-121. Thomas, Springfield, Ill.

Menecly, G. R. and Wells, E. B. (1946) Serious air embolism during blood donation. J. Am. med. Ass. 132, 141-143.

Heppner, F. (1952) Air embolism eight hours after ventriculography. Acta radiol. 38, 294-298.

Michenfelder, J. D., Terry, H. R., Daw, E. F. and Miller, R. H. (1966) Air embolism during neurosurgery. Anesth. Analg. curr. Res. 45, 390-395.

Miller, B. J., Gibbon, J. H., Greco, V. F., Cohn, C. H. and Allbritten, F. F. (1953) The use of a vent for the ventricle as a means of avoiding air embolism to the systemic circulation during open cardiotomy with the maintenance of the cardiorespiratory function of animals by pump oxygenator. Surg. Forum, Am. Co. of Surg. 4, 29-33.

Miller, D. R. and Allbritten, F. F. (1960) "Coronary Suction" as a source of air embolism: An experimental study using the Kay-Cross oxygenator. Ann. Surg. $151,75-84$.

Moore, R. M. and Braselton, C. W., Jr. (1940) Injections of air and of carbon dioxide into pulmonary vein. Ann. Surg. 112, 212-218.

Munson, E. S. and Merrick, H. C. (1966) Effect of nitrous oxide on venous air embolism. Anesthesiology 27, 783-787.

Musgrove, J. E. and MacQuigg, R. E. (1952) Successful treatment of air embolism. J. Am. med. Ass. 150, 28.

Mylks, G. W., Jr., Brown, A. B. and Robinson, C. N. (1947) Air embolism during labour. Can. med. Ass. J. 56, 427-429.

Nichols, H. T., Morse, D. R. and Hirose, T. (1958) Coronary and other air embolization occuring during open-heart surgery. Surgery 43, 236-244.

Nicholson, M. J. and Crehan, J. P. (1956) Emergency treatment of air embolism. Anesth. Analg. 35, 634-643.

Nun, J. F. (1959) Letter to editor. Anaesthesia 14, 413.

Olim, C. B. and Cinti, A. (1954) Meconium ileus: new method of relieving obstruction. Ann. Surg. 140, 736-740.

Oppenheimer, M. J., Durant, T. M. and Lynch, P. (1953) Body position in relation to venous air embolism and the associated cardiovascular-respiratory changes. Am.J. med.Sci. 225, 362-373.

Oppenheimer, M. J., Durant, T. M., Stauffer, H. M., Stewart, G. H., III, Lynch, P. R., and Barrera, F. (1956) In vivo visualization of intra-casdiac structures with gaseous carbon dioxide. Am. J. Physiol. 186, 325-334.

Pang, L. Q. (1952) Air embolism during lavage of the maxillary sinus. Laryngoscope 62, 1205-1224.

Partridge, A. J. (1943) Third case of air embolism reported vaginal insufflation. $B r$. med. J. 2, 329.

Pickren, J. W., Nigigasyan, G. and Kerr, J. M. (1959) Air embolism during intravenous infusions. N. Y. med. J. 59, 493-495.

Pierce, S. J. S. (1936) Death from vaginal insufflation (during pregnancy). Can. med. Ass. J. 35, 668-669.

Pollak, M. (1933) Air embolus. Am. Rev. Tuberc. 28, 187-195.

Ranson, C. L., Londoes, R. R. and McLelland, R. (1956) Air embolism following retroperitoneal pneumography. J. Urol. 76, 664-670.

Richardson, H. F., Coles, B. C. and Hall, G. E. (1937) Experimental gas embolism. J. Intravenous air embolism. Can. med. Ass. J.36, 584-588.

Rickles, N. H. and Joshi, B. A. (1963) Death from air embolism during root canal therapy. J. Am. dent. Ass. 67, 397-404.

Rosenthal, T. B. (1948) The effect of temperature on $\mathrm{pH}$ of blood and plasma in vitro. J. biol. Chem. 173, 25-30.

Ross. J., Jr. (1959) Factors influencing the formation of bubbles in blood. Trans. Am. Soc. artif. internal Organs 5, 140-147.

Rotem, C. E., Greig, J. H. and Walters, M. B. (1967) Air embolism to the pulmonary artery during insertion of transvenous endocardial pacemaker. J. thorac. cardiovasc. Surg. 53, 562-565.

Roesch, M., Miyatake, S. and Bollinger, C. M. (1960) Continuing hazard of air embolism during pressure transfusion. J. Am. med. Ass. 172, 1476-1482.

Rukstinat, G. (1931) Experimental air embolism of coronary arteries. J. Am. med. Ass. 96, 26-28. 
Rukstinat, G. and Le Count, E. R. (1928) Air in coronary arteries. J. Am. med. Ass. 91, 1776-1779.

Russ, F. H., Glenn, D. L. and Gianturco, C. (1953) Gas embolism during entra-peritoneal insufflation. Radiology 61, 637-638.

Schlaepfer, K. (1922) Air embolism following various diagnostic and therapeutic procedures in diseases of the pleura and lungs. Bull. Johns Hopkins Hosp. 33, 321-330.

Schmidt, P. J. and Kevy, S. V. (1958) Air embolism-A hazard during phlebotomy. New Engl. J. Med. 258, 424-427.

Senning, A. (1952) Ventricular fibrillation during entracorporeal circulation used methods to prevent air embolism and to facilitate intracardiac operations. Act. chir. scand. Suppl. 171, 7-72.

Selman, M. W., McAlpine, W. A., Albregt, H. and Ratan, R. (1967) An effective method of replacing air in the chest with $\mathrm{CO}_{2}$ during open-heart surgery. $J$. thorac. cardiovasc. Surg. 53, 618-622.

Serimgeoier, J. W. F. and Carrick, J. E. (1955) Fatal air embolism associated with ruptured uterus. Lancet $1,485-487$.

Shapiro, H. A. (1965) The diagnosis of death from delayed air embolism. J. forens. Med. 12,3-7.

Shaw, A., Cooperman, A. and Fusco, J. (1967) Gas embolism produced by hydrogen peroxide. New Engl. J. Med. 277, 238-241.

Shires, T. and O'Banion, J. (1958) Successful treatment of massive air embolism producing cardiac arrest. J. Am. med. Ass. 167, 1483-1484.

Shivpuri, D. N., Viswanothan, R., Sharma, M. L. and Singh, P. P. (1959) A pre-symptomatic diagnostic sign of venous air embolism. J. Indian med. Ass. 33, 86-88.

Silver, M. D. and Evans, T. N. (1968) Air embolism-a discussion of maternal mortality with a report of one survivor. Obstet. Gynec. 31, 403-405.

Simpson, K. (1942) Air accidents during transfusion. Lancet 1, 697-698.

Spencer, F. C., Rossi, N. P., Yu, S. C. and Koepke,
J. A. (1965) The significance of air embolism during cardiopulmonary bypass. $J$. thorac. cardiovasc. Surg. $49,615-634$.

Stallworth, J. M., Martin, J. B. and Postlethwait, R. W. (1950) Aspiration of the heart in air embolism. J. Am. med. Ass. 143, 1250-1253.

Starr, A. (1960) The mechanism and prevention of air embolus during correction of congenital cleft nutral valve. $J$. thorac. cardiovasc. Surg. 39, 808-814.

Swan, H. (1956) Hypothermia for general and cardiac surgery. Surg. Clins. N. Am. 36, 1009-1024.

Thomas, K. F. M. (1955) Air embolism following antral lavage. J. Lar. Otol. 69, 829-832.

Tisovec, L. and Hamilton, W. K. (1967) Newer considerations in air embolism during operation. J. Am. med. Ass. 201, 376-377.

Van Allen, C. M. and Hrdina, L. S. (1929) Air embolism from the pulmonary vein: A clinical and experimental study. Archs Surg. 19, 567-599.

Vischer, M. B. (1939) The restriction of the coronary flow as a general factor in heart failure. $J$. Am. med. Ass. 113, 987-990.

Wever, E. (1914) Cerebral air embolism. Beitr. Klin. Tuberk. 31, 159.

Weyrauch, H. M., Jr. (1940) Death from air embolism following perirenal insufflation, $J$. Am. med. Ass. 114, $652-653$.

Whitaker, D. M., Blins, L. R., Berg, W. E., Twitty, V. C. and Harris, M. (1945) Mascular activity and bubble formation in animals decompressed to simulated altitudes. J. Gen. Physiol. 28, 213-224.

Wolfe, J. B. and Robertson, H. F. (1935) Experimental air embolism. Ann. int. Med. 9, 162.

Wright, R. R. (1962) Experimental pulmonary hypertension produced by recurrent air emboli. Med. Thorac. 19, 231-235.

Wycoff, C. and Cann,J. E. (1966) Experimental pulmonary air embolism in dogs. Calif. Med. 105, 361-376.

Yeakel, A. E., (1968) Lethal air embolism from plastic blood-storage container. J. Am. med. Ass. 204, 267-269. 